\title{
Application of a coupled homogenization-damage model to masonry tunnel vaults
}

Omar Moreno Regan ${ }^{1}$, Emmanuel Bourgeois ${ }^{1}$, Anne-Sophie Colas ${ }^{1}$, Patrice Chatellier ${ }^{1}$

Alain Desbordes ${ }^{2}$, Jean-François Douroux ${ }^{2}$

${ }^{1}$ Université Paris-Est, IFSTTAR

14-20 Boulevard Newton

Cité Descartes, Champs sur Marne

F-77447 Marne la Vallée Cedex 2, France

omarmorenoregan@hotmail.com

emmanuel.bourgeois@ifsttar.fr

anne-sophie.colas@ifsttar.fr

patrice.chatellier@ifsttar.fr

${ }^{2}$ RATP

50 Rue Roger Salengro

94724 Fontenay-sous-bois, France

alain.desbordes@ratp.fr

jean-francois.douroux@ratp.fr

Corresponding author:

Omar Moreno Regan

Université Paris-Est, IFSTTAR

omarmorenoregan@hotmail.com 
Keywords: Masonry, Tunnel, Vault, Damage, Homogenization, Finite element

\begin{abstract}
This paper presents an approach developed to study the behavior of the masonry vaulted tunnels in order to evaluate the serviceability state and failure load. An appropriate homogenization technique is used to simulate the global anisotropic behavior across the vault. The model takes into account isotropic damage in each component of the masonry and the variations of the directions of anisotropy in case of a vault. A set of comparisons with experimental tests allowed the validation of the proposed approach. Failure loads and deformation states are correctly assessed. The present model was programmed in the finite element code CESAR-LCPC.
\end{abstract}




\section{Introduction}

Masonry vaults are very common in numerous historical buildings, bridges and tunnels. The use of masonry for new constructions declined considerably since the second half of the 20th century, but these structures still exist and their maintenance necessitates the study of their behavior. In particular, the objective of this paper is to develop a model to study the behavior of the masonry vaulted tunnels of the Paris metro, whose infrastructure is mostly underground and was built predominantly in the early 20th century. Such structures can withstand displacements in the order of several tens of millimeters without reaching failure, and this is not properly accounted for by numerical models (notably elastoplastic models).

Masonry is a heterogeneous material made of elementary blocks (bricks or stone blocks) and mortar joints. Its behavior has been studied in numerous scientific publications (see for instance the survey provided by (Angelillo, 2014)). Before the 20th century, the calculation methods developed for masonry vaults were focused on the evaluation of their bearing capacity (Benvenuto, 1991), on the basis of graphic analysis of the static equilibrium of the structure. More recently, masonry vaults have been analyzed by means of limit analysis (Heyman, The safety of masonry arches, 1969), (Heyman, The Stone Skeleton, 1997), (Livesley, 1978) and of the yield design theory (Salençon, 1983), (Delbecq, 1982). However, such stability analyses do not allow to compute the deformation of the structure when the applied load bring it close to failure.

The development of modern displacement computation approaches and numerical methods, permits to evaluate the deformation of any structure under complex conditions, in all stages of an incremental loading. Among the different numerical techniques to model masonry structures (Roca, Cervera, Gariup, \& Pela, 2010), the finite element method is frequently used. It is especially adapted to discuss the interaction between the masonry vault of a tunnel and the surrounding ground, which generally exhibits a complex behavior that can be conveniently taken into account in the framework of the finite element method. Three modeling strategies can be distinguished for masonry structures (Lourenço P. , 1996):

1) detailed micro-modeling: each component of the masonry, i.e. blocks, joints and interfaces are modeled separately, with a constitutive law for each component;

2) simplified micro-modeling, where the blocks are geometrically expanded to account for mortar, while the mortar behavior is reflected in the interface constitutive law; 
3) macro-modeling, in which all components of the masonry are represented as a continuous homogeneous medium and "equivalent" to the masonry.

Given the computational effort required and the large number of necessary experimental data, the first two approaches are reserved for small masonry structures and for situations in which the local heterogeneities of the stress field are investigated. The macro- modeling is suitable for large structures. Several examples of these three approaches can be found in (Angelillo, 2014) and (Roca, Cervera, Gariup, \& Pela, 2010).

The objective in our study is to develop a model for masonry vaults. To this end, a macro-modeling approach was adopted using a homogenization technique proposed by (Zucchini \& Lourenço, A coupled homogenisation-damage model for masonry cracking, 2004) to transform the masonry into an equivalent continuum medium. Then, an isotropic damage model is used to represent the nonlinear behavior of the masonry components, which describes the degradation of the material (stiffness reduction) before the macroscopic failure (Murakami, 2012). Variations of the directions of the block-mortar bond in the vault are also taken into account.

Damage models have been used by several authors to study masonry structures under various loading conditions: walls under seismic loads (Callerio \& Papa, 1998), (Maier, Papa, \& Nappi, 1991), (Papa, 1995), (Toti, Gattulli, \& Sacco, 2015), (Wawrzynek \& Cincio, 2005); walls under a point shear load (Addessi, Marfia, \& Sacco, A plastic nonlocal damage model, 2002), (Addessi \& Sacco, A multi-scale enriched model for the analysis of masonry panels, 2012), (Berto, Saetta, Scotta, \& Vitaliani, 2004), (Uva \& Salerno, 2006), (Zucchini \& Lourenço, A micro-mechanical homogenisation model for masonry: Application to shear walls, 2009); walls under in-plane vertical or horizontal loads (Greco, Leonett, Luciano, \& Nevone Blasi, 2016), (Luciano \& Sacco, 1997), (Massart, Peerlings, \& Geers, 2004), (Quinteros, Oller, \& Nallim, 2012), (Tesei \& Ventura, 2016), (Zahra \& Dhanasekar, 2016), (Zucchini \& Lourenço, A coupled homogenisation-damage model for masonry cracking, 2004), (Zucchini \& Lourenço, Mechanics of masonry in compression: Results from a homogenisation approach, 2007); vaults under different loads (Creazza, Matteazzi, Saetta, \& Vitaliani, 2002), (Pelà , Cervera, \& Roca, 2011), (Stablon, Sellier, Domede, Plu, \& Dieleman, 2012); and bridges (Domède, 2006), (Domede, Sellier, \& Stablon, 2013) ; among others. Most of the studies on masonry using damage models consider a wall subjected to in-plane loads or earthquake motions; the case of vaults 
(bridge or buried arches) is not commonly discussed. Old masonry tunnels are even more rarely studied: the analysis of buried masonry vaults is the focus of our study.

The model for masonry vaults was programmed in the finite element code CESAR-LCPC (ajouter une référence à Humbert P., Dubouchet A., Fezans G., Remaud D. (2005) CESAR-LCPC, un progiciel de calcul dédié au Génie Civil. Bulletin des Laboratoires des Ponts et Chaussées 256-257: 7-37.), a software package dedicated to civil engineering and geotechnical engineering applications, developed since the 1980's by the French Institute of science and technology for transport, development and networks (IFSTTAR).

In this paper we present firstly the numerical implementation, followed by a set of comparisons with experimental tests which allowed the validation of the proposed approach.

\section{Homogenization-damage model for masonry}

\subsection{Masonry homogenization}

The process of homogenization consists in replacing a heterogeneous medium by an equivalent homogeneous one. In the case of masonry, the very regular geometrical pattern of bricks or blocks and mortar joints makes it possible to assume that the heterogeneous masonry material is comparable to a composite one with a periodic microstructure. Such a medium is defined by a "basic cell" whose graphic repetition represents the whole structure (Fig. 1).

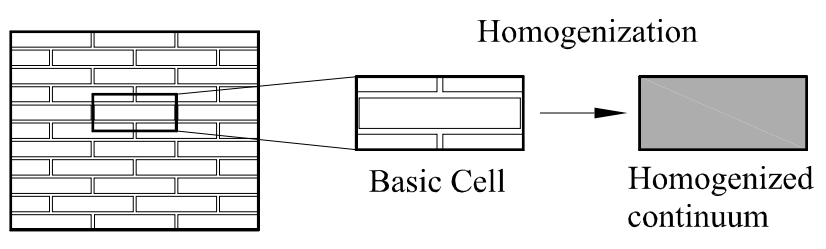

Fig. 1 Basic cell of a masonry wall (Zucchini \& Lourenço, A micro-mechanical model for the homogenisation of masonry, 2002)

The geometry of the basic cell and the behavior of its components, i.e. blocks and joints, are used to derive the constitutive law of the homogenized continuum. This procedure is referred as a micro-mechanical model for the homogenization of masonry by (Zucchini \& Lourenço, A micro-mechanical model for the homogenisation of masonry, 2002), and gives the homogenized macroscopic stiffness matrix $H$ that connects 
the macroscopic stresses $\Sigma^{0}$ to the macroscopic strains $\mathrm{E}^{0}$ in the basic cell. This matrix is then used to compute forces and displacements in the structure.

A state of the art on the homogenization techniques for masonry can be found in (Lourenço, Milani, Tralli, \& Zucchnini, 2007). Homogenization can be carried out by numerical or analytical means. In this paper a simplified analytical approach was used.

\subsection{Nonlinear homogenization}

Among the homogenization techniques, the analytical engineering approach proposed by (Zucchini \& Lourenço, A micro-mechanical model for the homogenisation of masonry, 2002) for the masonry was chosen. This technique aims to replace the complex behavior of the basic cell with a simplified one. Initially developed for the elastic range, the approach was extended to the nonlinear range in (Zucchini \& Lourenço, A coupled homogenisation-damage model for masonry cracking, 2004), (Zucchini \& Lourenço, Mechanics of masonry in compression: Results from a homogenisation approach, 2007) and (Zucchini \& Lourenço, A micro-mechanical homogenisation model for masonry: Application to shear walls, 2009) for various loading situations. This technique will be referred as the model of Zucchini \& Lourenço in the following.

The approach is based on the superposition principle. The elastic response to the basic cell subjected to a uniform macroscopic stress state is determined by studying separately six basic loading conditions: three cases of normal loading and three cases of pure shear loading, along the axes of the local coordinate system (LCS) (Fig. 2 a). For each load case, the value of one component of the macroscopic stress tensor is imposed to the basic cell, the other components being zero.

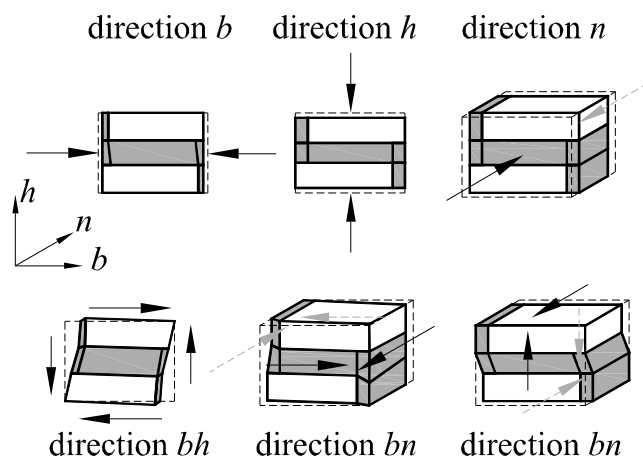

a) Six elementary loading cases

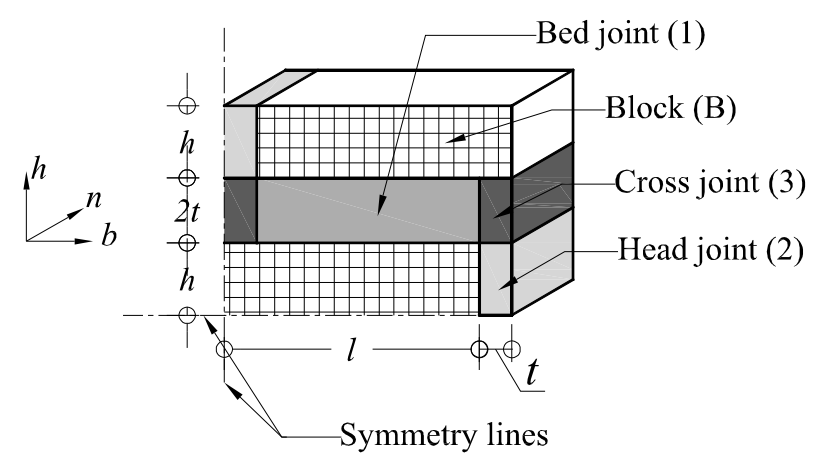

b) Components of the basic cell 
Fig. 2 Quarter basic cell in the masonry of the model of Zucchini \& Lourenço (Zucchini \& Lourenço, A micromechanical model for the homogenisation of masonry, 2002)

Because of symmetry conditions, only one quarter of the basic cell is studied. It is divided into four components: in one hand the blocks, and in the other hand, the mortar joints, with the horizontal, vertical and cross joints (Fig. 2 b)

By introducing the equilibrium between micro and macro forces in the basic cell boundaries and interfaces, the compatibility of the deformation of the components and using Hooke's law, together with other simplifying assumptions, a system of equations for each load case is introduced, which allows to compute the stresses and strains in each component, under a given macroscopic stress field.

In the nonlinear range, the model associates a scalar damage variable to each component of the basic cell (i.e. joints and blocks). The problem is treated in an incremental way: under increasing load, the homogenization technique must account for the damage in each component, and consequently update the internal stresses and elastic parameters. Damage is evaluated using a simple Rankine criterion (i.e. only the maximum principal stress is compared to the tensile strength).

The great interest of this approach lies in the fact that the nonlinear anisotropic constitutive law of the masonry is obtained by solving a set of algebraic equations, and it is not necessary to solve an auxiliary boundary problem on the basic cell by means of a finite element simulation.

A damage coefficient $r^{k}=\left(1-d^{k}\right)$ is introduced for each component stress, where $d$ is the damage variable, $k=1,2,3$ and $B$, respectively for the horizontal, vertical, and cross joint, and block (Fig. 2 b). The variable $d$ is evaluated with the model presented in paragraph 3.1.

A system of equations is written in terms of effective stresses for the case of the quarter cell subjected to a normal macroscopic stress $\sigma_{i i}^{0}$ (Fig. 2 a). For instance, equilibrium at the right boundary leads to:

$$
l r^{B} \sigma_{h h}^{B}+t r^{2} \sigma_{h h}^{2}=(l+t) \sigma_{h h}^{0}
$$

Superscripts $1,2,3$ and $B$, indicate the component, respectively the horizontal, vertical, and cross joint, and block. The superscript 0 represents homogenized cell variables. The subscripts $b, h$, and $n$ represents the local coordinate system (LCS) of the basic cell (Fig. 2 b). See (Zucchini \& Lourenço, A micro-mechanical 
model for the homogenisation of masonry, 2002) and (Zucchini \& Lourenço, A coupled homogenisationdamage model for masonry cracking, 2004) for the full set of the equations. The system of equations can be expressed as:

$$
A_{i j}^{a} \sigma_{j}=\sigma_{i}^{0}
$$

where $\sigma=\left\{\sigma_{b b}^{1}, \sigma_{b b}^{2}, \bar{\sigma}_{b b}^{B}, \sigma_{h h}^{1}, \sigma_{h h}^{2}, \sigma_{h h}^{B}, \sigma_{n n}^{1}, \sigma_{n n}^{2}, \sigma_{n n}^{B}\right\}^{T}$ represents the internal stresses in the basic cell, $\sigma^{0}=\left\{0,0, \sigma_{b b}^{0}, \sigma_{h h}^{0}, \sigma_{n n}^{0}, 0,0,0,0\right\}^{T}$ a vector containing the macroscopic stresses and $A^{a}$ a matrix that contains the geometrical and mechanical properties of the components. In the proposed approach, it is assumed that the horizontal stresses varies linearly inside the block, and $\bar{\sigma}_{b b}^{B}$ denotes the average value in the block.

Homogenized strains are calculated once the system of equations (2) is solved. Finally, Young's moduli and Poisson's ratios are calculated from average strains and stresses. For example, in the direction $b$, boundary imposed conditions to the basic cell $\sigma_{b b}^{0} \neq 0, \sigma_{h h}^{0}=\sigma_{n n}^{0}=0$, lead to:

$$
E_{b}=\frac{\sigma_{b b}^{0}}{\varepsilon_{b b}^{0}} \quad v_{b h}=-\frac{\varepsilon_{h h}^{0}}{\varepsilon_{b b}^{0}}
$$

Each case of shear stress forms a separated system of equations. Strains are then calculated in all the components, i.e. blocks and joints, and finally the corresponding macroscopic strains. It is then possible to evaluate the macroscopic homogenized stiffness matrix $H$.

\section{Improved model for masonry vaults}

The following modifications of the model are proposed:

- the isotropic damage model used to characterize the nonlinear behavior of each component in the masonry is different from the model initially proposed;

- the model takes into account variations of the directions of the block-mortar bond in the vault;

- a regularization technique is adopted to reduce the dependence of the solution regarding the finite element mesh, in the numerical modeling of the softening law. 


\subsection{Isotropic damage model for the components}

The model of Zucchini \& Lourenço uses a simple Rankine damage criterion to study the behavior in traction (Zucchini \& Lourenço, A coupled homogenisation-damage model for masonry cracking, 2004) and an elastoplastic model in compression (Zucchini \& Lourenço, Mechanics of masonry in compression: Results from a homogenisation approach, 2007), in each component of the masonry. Instead of this complex model, we used a single isotropic damage model.

The state of damage for isotropic models (Lemaitre \& Desmorat, Engineering Damage Mechanics, 2005) is controlled by a scalar variable $d$ that ranges from 0 to 1,0 representing the undamaged material and 1 corresponding to fracture, such that the damaged modulus is given by $E_{d}=E_{0}(1-d)$, where $E_{0}$ is the elastic modulus without damage. A modified version of the Mazars model (Mazars, 1986) for concrete proposed by (Davenne, Saouridis, \& Piau, 1989) is used. This model considers an equivalent strain $\tilde{\varepsilon}$ at each material point, which depends on the three-dimensional state of strain:

$$
\widetilde{\varepsilon}=\gamma \sqrt{\left\langle\varepsilon_{1}\right\rangle_{+}^{2}+\left\langle\varepsilon_{2}\right\rangle_{+}^{2}+\left\langle\varepsilon_{3}\right\rangle_{+}^{2}}
$$

where $\varepsilon_{i}(i=1,2,3)$ represent the principal strains, $\left\langle\varepsilon_{i}\right\rangle_{+}=\varepsilon_{i}$ if $\varepsilon_{i} \geq 0$; or 0 if not. In eq. (4) the coefficient $\gamma$ is defined by the following expression:

$$
\gamma=-\frac{\sqrt{\left\langle\bar{\sigma}_{1}\right\rangle_{-}^{2}+\left\langle\bar{\sigma}_{2}\right\rangle_{-}^{2}+\left\langle\bar{\sigma}_{3}\right\rangle_{-}^{2}}}{\left\langle\bar{\sigma}_{1}\right\rangle_{-}^{2}+\left\langle\bar{\sigma}_{2}\right\rangle_{-}^{2}+\left\langle\bar{\sigma}_{3}\right\rangle_{-}^{2}}
$$

where $\bar{\sigma}_{i}$ represents the principal effective stress in the direction $i$; and $\left\langle\sigma_{i}\right\rangle_{-}$is the negative part of the principal effective stress: $\left\langle\sigma_{i}\right\rangle_{-}=\sigma_{i}$ if $\sigma_{i} \leq 0$; or 0 if not. The value of $\gamma$ is bounded between 0 and 1 and calculated only when at least a one principal effective stress is negative, i.e. in compression.

The damage variable evolves if the equivalent strain $\tilde{\varepsilon}$ reaches a threshold value $\varepsilon_{D 0}$. Following (Mazars, 1986), this threshold is the strain at the maximum stress in a uniaxial direct tension test. Assuming that the behavior is linear up to the maximum tensile stress we can write $\varepsilon_{D 0}=f_{t} / E_{0}$, where $f_{t}$ is the tensile strength. The damage criterion is then written: 


$$
F=\widetilde{\varepsilon}-\widetilde{\varepsilon}_{M} \leq 0
$$

where $\widetilde{\varepsilon}_{M}$ is the actual threshold, equal to the initial threshold $\varepsilon_{D 0}$ if it has never been reached, or the maximum value reached by $\tilde{\varepsilon}$ otherwise. The damage variable $d$ is a linear combination of two damage variables (Mazars, 1986), $d_{t}$ and $d_{c}$, associated respectively to the tensile and compression stresses:

$$
d=\alpha_{t} d_{t}+\alpha_{c} d_{c}
$$

In the absence of traction $\alpha_{t}=0$, in the absence of compression $\alpha_{c}=0$, and in all cases $\alpha_{t}+\alpha_{c}=1$, see (Mazars, 1986) for a detailed definition of $\alpha_{t}$ and $\alpha_{c}$. The evolution laws of the two variables of damage are:

$$
\begin{gathered}
d_{c}=1-\frac{\varepsilon_{D 0}\left(1-A_{c}\right)}{\widetilde{\varepsilon}_{M}}-\frac{A_{c}}{\exp \left[B_{c}\left(\widetilde{\varepsilon}_{M}-\varepsilon_{D 0}\right)\right]} \\
d_{t}=1-\frac{\varepsilon_{D 0}}{\widetilde{\varepsilon}_{M}} \exp \left[-B_{t}\left(\widetilde{\varepsilon}_{M}-\varepsilon_{D 0}\right)\right]
\end{gathered}
$$

where $A_{c}$ and $B_{c}$ are parameters obtained experimentally from the stress-strain curves of a compression test. The equation for $d_{t}$ in (8) is a modified expression, from that of (Mazars, 1986), proposed by (La Borderie, 2003) as a regularization technique in traction, to avoid the well-known excessive mesh sensitivity problems in the finite element modeling of the softening behavior of the damage law, see (Murakami, 2012). The parameter $B_{t}$ depends on the characteristic length $l_{c}$, the mode I fracture energy $G_{f t}$, and the tensile strength of the material $f_{t}$ :

$$
B_{t}=\frac{l_{c} f_{t}}{G_{f t}}
$$

where $l_{c}=\sqrt{S}$, and $S$ is the area (or volume) of the finite element to which the integration point belongs. The mode I fracture energy is assumed to be a material property. This is another difference with respect to the model of Zucchini \& Lourenço, in which the characteristic length is taken equal to the component dimension perpendicular to the crack direction, producing high mesh-sensitivity because $l_{c}$ is a constant quantity. Introducing damage in each homogeneous isotropic component makes it possible to reproduce implicitly the global anisotropic damage behavior of the masonry. 


\subsection{Strain driven problem}

For the coupling of the numerical homogenization procedure with damage, it is convenient to evaluate the stresses and strains in the basic cell by imposing a macroscopic incremental strain field instead of a stress field.

When studying traction parallel to the bed joint of the masonry, the model of Zucchini \& Lourenço imposes to the basic cell a macroscopic horizontal strain and null macroscopic stress in the other directions (Zucchini \& Lourenço, A coupled homogenisation-damage model for masonry cracking, 2004); when studying compression, a macroscopic vertical strain and null macroscopic stress in the other directions (Zucchini \& Lourenço, Mechanics of masonry in compression: Results from a homogenisation approach, 2007). In our study a uniform strain field is imposed, instead of these mixed boundary conditions.

In practice, we decompose the macroscopic strain tensor into two contributions: one due to the normal strain and other due to shear strain. Two auxiliary problems on the basic cell must be solved. The damage in each component depends on the sum of the stresses in the given component obtained for each auxiliary problem. This approach was adopted by (Zucchini \& Lourenço, A micro-mechanical homogenisation model for masonry: Application to shear walls, 2009). In our study, we adopt the following simplifying assumption: damage in components is caused only by the macroscopic strains $\varepsilon_{b b}^{0}, \varepsilon_{h h}^{0}, \varepsilon_{n n}^{0}$ (Fig. 3), the strain $\varepsilon_{b h}^{0}$, considered small compared to strains $\varepsilon_{i i}^{0}$, is neglected. With this assumption, a single auxiliary problem must be solved to compute internal stresses and strains of each component within the basic cell.

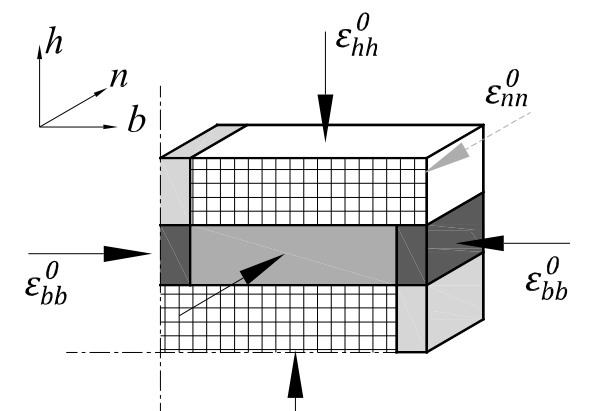

Fig. 3 Strain field applied to the quarter basic cell $\varepsilon_{h h}^{0}$

Thus the system of equations (2) becomes:

$$
A_{i j}^{b} \sigma_{j}=\varepsilon_{i}^{0}
$$


where $\quad \sigma=\left\{\sigma_{b b}^{1}, \sigma_{b b}^{2}, \bar{\sigma}_{b b}^{B}, \sigma_{h h}^{1}, \sigma_{h h}^{2}, \sigma_{h h}^{B}, \sigma_{n n}^{1}, \sigma_{n n}^{2}, \sigma_{n n}^{B}\right\}^{T} \quad$ represents $\quad$ the $\quad$ internal stresses, $\varepsilon^{0}=\left\{0,0, \varepsilon_{b b}^{0}, \varepsilon_{h h}^{0}, \varepsilon_{n n}^{0}, 0,0,0,0\right\}^{T}$ a vector containing the macroscopic strains and $A^{b}$ a matrix that contains the geometrical and mechanical properties of the components. A complete presentation of the system of equations can be found in (Moreno Regan, 2016).

\subsection{Homogenized damaged parameters}

For a given macroscopic strain field, stresses $\sigma$ in the components are obtained after resolution of the system (10), and then the damage coefficients $r^{k}=\left(1-d^{k}\right)$ are calculated for each component using the model of paragraph 3.1 .

Given the fact that a strain field is imposed to the basic cell, it is difficult to evaluate the Poisson's ratios. It is proposed here to solve firstly the system (10) that gives the damage coefficient $r^{k}$. Secondly, the coefficients $r^{k}$ previously obtained are injected into the system of equations where an arbitrary macroscopic stress $\sigma_{i j}^{0}=1 \mathrm{~Pa}$ is imposed with different boundary conditions, to finally calculate the damaged elastic moduli and the Poisson's ratios.

\subsection{Geometrical considerations for the vault}

The model defined in the previous paragraphs was presented with respect to the directions of the basic cell, denoted $b, h$ and $n$. For a wall, the orientation of the local axes is constant. In a masonry vault (Fig. 4 a), the orientation of the block-mortar bond varies and it is necessary to take it into account: the global coordinate system (GCS) in which the finite element mesh is constructed and the local coordinate system (LCS) which follows the orthotropic directions of the masonry (Fig. 4). The directions $b$ and $h$ are in the plane while the direction $n$ is out of the plane.

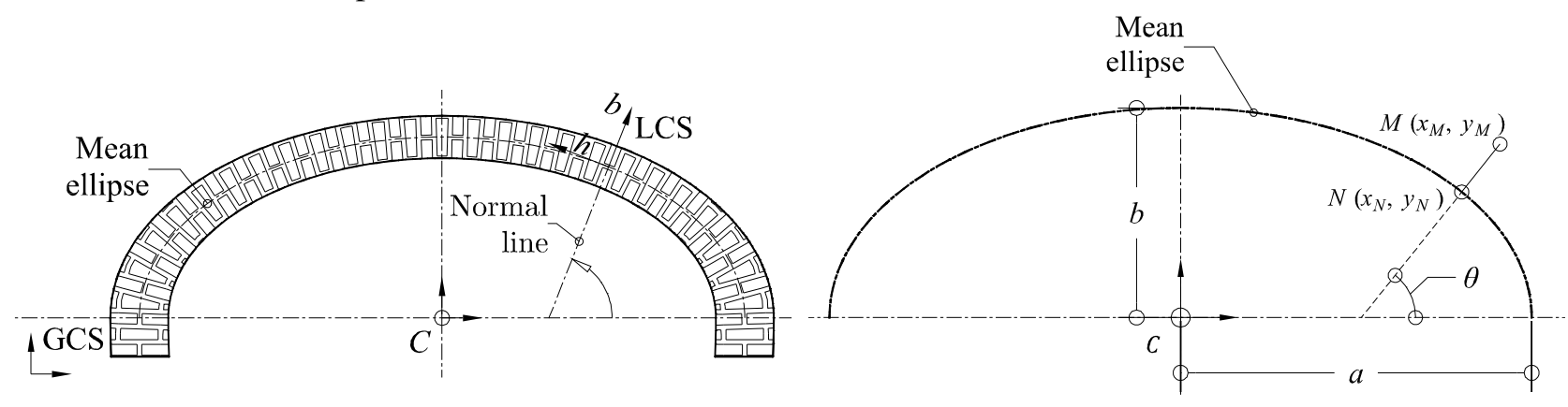

a) Definition of the coordinate systems

b) Normal projection of the $M$ point into the mean ellipse

Fig. 4 Geometry of the masonry vault of a tunnel 
The vault geometry is defined by the intrados and the extrados, both of elliptical shape, making it possible to take into account a wide variety of geometries. A fictitious "mean ellipse" is defined in the vault, midway between the intrados and the extrados, centered in $C$, with semi-axes $a$ and $b$ (Fig. 4b). Each point $M\left(x_{M}, y_{M}\right)$ of the vault is associated with its projection onto the mean ellipse, denoted by $N\left(x_{N}, y_{N}\right)$, and the local masonry directions $b$ and $h$ are taken equal to the normal and the tangent to the mean ellipse. We introduce the angle $\theta$ that defines the position of the point $M$ with respect to the horizontal axis and the normal projection to the mean ellipse (Fig. 4 b).

The coordinates of the point $N\left(x_{N}, y_{N}\right)$ are given by

$$
\begin{aligned}
& x_{N}=x_{M}\left(1-\frac{2 k}{a^{2}}\right) \quad \text { where } k=\frac{\frac{2 x_{M}^{2}}{a^{2}}+\frac{2 y_{M}^{2}}{b^{2}}-1}{\frac{4 x_{M}^{2}}{a^{4}}+\frac{4 y_{M}^{2}}{b^{4}}} \\
& y_{N}=y_{M}\left(1-\frac{2 k}{b^{2}}\right)
\end{aligned}
$$

and the angle $\theta$ is defined by:

$$
\theta=\arctan \left(\frac{y_{N} a^{2}}{x_{N} b^{2}}\right)
$$

The angle $\theta$ is positive counterclockwise. For $\theta=90^{\circ}$ the point is at the keystone of the vault.

The strain field applied to the basic cell in paragraph 3.2 has to be expressed in the LCS. In a 2D study, the transition from the GCS to the LCS is carried out by performing the following operation:

$$
\varepsilon_{i}^{0}=Q_{i j} \mathrm{E}_{j}^{0}
$$

where $\mathrm{E}^{0}$ is the macroscopic strain vector in the GCS (with the conventions of Fig. 4) and $\varepsilon^{0}$ the macroscopic strain vector in the LCS. The matrix $Q$ is given by:

$$
Q=\left[\begin{array}{ccc}
\cos ^{2} \theta & \sin ^{2} \theta & 2 \cos \theta \sin \theta \\
\sin ^{2} \theta & \cos ^{2} \theta & -2 \cos \theta \sin \theta \\
-\sin \theta \cos \theta & \sin \theta \cos \theta & \cos ^{2} \theta-\sin ^{2} \theta
\end{array}\right]
$$

where $\theta$ is computed with equation (12). 


\subsection{Damage tensor}

The orthotropic damaged stiffness matrix $C^{d}$ (see eq.(18) below) is given implicitly by homogenizationdamage technique without the formulation of a damage tensor variable. To display the state of damage of the vault, it is interesting to calculate an orthotropic damage tensor, using the strain equivalence principle (Lemaitre, A course in damage mechanics, 1992). We can write:

$$
D_{i j}=I_{i j}-\left(M^{-1}\right)_{i j}
$$

where $I$ is the identity second order tensor; $M$ is a second order tensor called effective damage tensor according to (Murakami, 2012), which transforms the stress tensor $\sigma$ into effective stress tensor $\bar{\sigma}$ and is expressed as

$$
M_{i j}=C_{i k}^{0} S_{k j}^{d}
$$

$C_{i k}^{0}$ is the undamaged stiffness matrix in the LCS and $S_{i j}^{d}=\left[\left(C^{d}\right)^{-1}\right]_{i j}$. This produces an asymmetrical second order tensor $D$ :

$$
D=\left[\begin{array}{cccccc}
D_{11} & D_{12} & D_{13} & 0 & 0 & 0 \\
D_{21} & D_{22} & D_{23} & 0 & 0 & 0 \\
D_{31} & D_{32} & D_{33} & 0 & 0 & 0 \\
0 & 0 & 0 & D_{44} & 0 & 0 \\
0 & 0 & 0 & 0 & D_{55} & 0 \\
0 & 0 & 0 & 0 & 0 & D_{66}
\end{array}\right]_{L C S}
$$

The tensor $D$ expresses damage in the LCS (Fig. 4). Thus, for example $D_{l 1}$ can be seen as the degradation of the $E_{b}$ module and $D_{22}$ as degradation of $E_{h}$. The evaluation of the anisotropic damage tensor is not needed to carry out the calculations, but provides the possibility to represent graphically the anisotropic damage state in the vault given by the model.

\section{Numerical implementation}

In our study, we propose to apply the homogenization-damage technique to each integration point of the finite element mesh in order to compute forces and displacements in the structure. 


\subsection{Global iterative resolution procedure}

In the finite element analysis of damage problems, an elastic solution is computed first, with the initial value of the damage parameters. At a local level, the strains induce a modification of the damage parameters (described in the following section), and of the stiffness of the material: the stress state must be updated to account for this stiffness reduction, which produces out-of-balance nodal forces. The procedure follows a classical Newton-Raphson iterative scheme.

More precisely, once the homogenized macroscopic parameters are obtained at the local level, the damaged stiffness matrix $C^{d}$ is updated in the LCS (see paragraph 3.4). In plane stress we have:

$$
C^{d}=\left[\begin{array}{ccc}
\frac{E_{b}}{1-v_{b h} v_{h b}} & \frac{E_{b} v_{h b}}{1-v_{b h} v_{h b}} & 0 \\
\frac{E_{b} v_{h b}}{1-v_{b h} v_{h b}} & \frac{E_{h}}{1-v_{b h} v_{h b}} & 0 \\
0 & 0 & G_{b h}
\end{array}\right]_{L C S}
$$

Then the damaged stiffness matrix $H^{d}$ in the GCS is computed:

$$
H_{k l}^{d}=T_{k i} C_{i j}^{d} P_{l j}
$$

where $T$ and $P$ are transformation matrices:

$$
T=\left[\begin{array}{ccc}
\cos ^{2} \theta & \sin ^{2} \theta & -\cos \theta \sin \theta \\
\sin ^{2} \theta & \cos ^{2} \theta & \cos \theta \sin \theta \\
2 \sin \theta \cos \theta & -2 \sin \theta \cos \theta & \cos ^{2} \theta-\sin ^{2} \theta
\end{array}\right] \quad P=\left[\begin{array}{ccc}
\cos ^{2} \theta & \sin ^{2} \theta & -2 \cos \theta \sin \theta \\
\sin ^{2} \theta & \cos ^{2} \theta & 2 \cos \theta \sin \theta \\
\sin \theta \cos \theta & -\sin \theta \cos \theta & \cos ^{2} \theta-\sin ^{2} \theta
\end{array}\right]
$$

Angle $\theta$ is computed with equation (12). Finally, the update of the macroscopic stresses $\Sigma^{0}$ is carried out:

$$
\Sigma_{i}^{0}=H_{i j}^{d} \mathrm{E}_{j}^{0}
$$

The numerical scheme is summarized in Box 1, where $m$ represents the global iteration. The global damage criterion $F_{G}$ adopted here is:

$$
F_{G}=\max \left\lfloor F_{c}^{k}\right\rfloor
$$

where $F_{c}^{k}$ represents the damage criterion of each component given by equation (6). 
Box 1 Global iterative algorithm for masonry vaults

(i) Compute incremental macroscopic stresses and strains in each integration point from $\left(H^{d}\right)_{m-1}$

(ii) Compute damage coefficients in basic cell, see Box 2

(iii) Check global criterion $F_{G}>0$ ?, Eq. (22)

YES: damage loading. Proceed to (iv)

NO: no further damage. Exit

(iv) Compute local damaged stiffness matrix $\left(C^{d}\right)_{m}$, Eq. (18)

(v) Compute damage tensor $D$ for display only, Eq. (17)

(vi) Update global stiffness matrix $\left(H^{d}\right)_{m}$, Eq. (19)

(vii) Update macroscopic stresses $\Sigma_{i}^{0}$, Eq. (21)

\subsection{Local iterative resolution procedure}

Since the stresses in each component depend on the damage coefficient $r^{k}=\left(1-d^{k}\right)$ and the damage variable $d^{k}$ depends on the stress state in each component, a local iterative process is necessary. It is performed at the basic cell level: for each strain increment $\varepsilon_{i i}^{0}$, the system (10) is solved to obtain the unknown internal stresses and strains in the cell components $(k=1,2,3$, and $B)$, using the damage coefficients of the previous iteration. Damaged coefficients are then updated using the model of paragraph 3.1, from the new stresses. The process is iterated until convergence of the coefficients $r^{k}$. It is considered that convergence is achieved when:

$$
p_{\max }<\eta \quad \text { with } p_{\max }=\max \left[p_{k}\right], \text { and } p_{k}=1-\frac{\min \left(r_{n-1}^{k}, r_{n}^{k}\right)}{\max \left(r_{n-1}^{k}, r_{n}^{k}\right)}
$$

where $n$ is the actual iteration in the basic cell and $\eta$ is the tolerance taken equal to $10^{-3}$. The procedure is summarized in Box 2. 
Box 2 Local iterative algorithm in the basic cell

For each integration point:

(i) Compute local macroscopic strains, Eq. (13)

(ii) Compute stresses and strains in all components with $\left(r^{k}\right)_{n-1}$, Eq. (10)

(iii) For each component:

Compute equivalent strain, Eq. (4)

Check damage criterion $F_{c}^{k}>0$ ? Eq. (6)

YES: damage loading. Proceed to (iv)

NO: no further damage. Exit

(iv) Update damage coefficients $\left(r^{k}\right)_{n}$

(v) Convergence? Eq. (23)

YES: Proceed to (vi)

NO: Proceed to (ii)

(vi) Update damaged homogenized parameters, see paragraph 3.3

\section{Validation}

The model presented above makes it possible to account for the strength and geometry of the mortar joints in the vault, since the homogenization technique is performed at each step of the loading process. It is possible to compare homogenized numerical results with experimental results provided that the results are analyzed at the appropriate scale (many authors have adopted this approach to validate numerical homogenized models for masonry: (Luciano \& Sacco, 1997), (Massart, Peerlings, \& Geers, 2004), (Quinteros, Oller, \& Nallim, 2012), (Uva \& Salerno, 2006), (Zucchini \& Lourenço, A micro-mechanical homogenisation model for masonry: Application to shear walls, 2009) and (Zucchini \& Lourenço, Mechanics of masonry in compression: Results from a homogenisation approach, 2007), among others).

The approach presented in the preceding paragraphs was applied to some experimental studies for validation purpose.

\subsection{Elementary validations}

We considered existing experimental studies in the literature to verify that the expected behavior is correctly reproduced. All FEM calculations were carried out in plane stress conditions. 


\subsubsection{Compression strength}

Tests on the compressive strength of masonry prisms by (McNary \& Abrams, 1985) are used to validate the numerical model. Two types of blocks were tested. The properties of the materials are presented in Appendix A. The geometric parameters are showed in Table 1. In the simulations, the vertical displacement is set to zero on the lower boundary, and a vertical displacement is imposed on the upper boundary. Finite element size is about $5 \mathrm{~cm}$.

Table 1 Properties of the prisms tested in compression (McNary \& Abrams, 1985)

\begin{tabular}{|c|c|c|c|c|c|}
\hline \multirow{2}{*}{ Ref } & \multicolumn{3}{|c|}{ Blocks dimensions (mm) } & \multirow{2}{*}{$\begin{array}{l}\text { Mortar thickness } \\
\qquad(\mathrm{mm})\end{array}$} & \multirow{2}{*}{$\begin{array}{l}\text { Prism size } \\
\qquad(\mathrm{mm})\end{array}$} \\
\hline & length & Height & depth & & \\
\hline Unit 1 & 200 & 57 & 98 & 9.5 & $200 \times 323$ \\
\hline Unit 2 & 194 & 55 & 89 & 9.5 & $200 \times 323$ \\
\hline
\end{tabular}

Results are showed in Table 2. Good agreement is observed for Unit 1 test with a $-1.9 \%$ deviation, whereas a less accurate numerical result is obtained for Unit 2 test with a $-11.7 \%$ deviation. A comparison with the numerical results by [48] for the same tests is also presented, these show $-2.7 \%$ and $6.6 \%$ deviations respectively.

Table 2 Comparison between the measured compressive strength (McNary \& Abrams, 1985) and numerical predictions (MPa)

\begin{tabular}{cccc}
\hline Prism & Experimental & Model & $\begin{array}{c}\text { Zucchini \& } \\
\text { Lourenço } \\
\text { (Zucchini \& } \\
\text { Lourenço, } \\
\text { Mechanics of } \\
\text { masonry in } \\
\text { compression: } \\
\text { Results from a } \\
\text { homogenisation } \\
\text { approach, } \\
\text { 2007) }\end{array}$ \\
\hline $\mathrm{U} 1 \mathrm{M}$ & 48.2 & 47.3 & 46.9 \\
$\mathrm{U} 2 \mathrm{M}$ & 37.7 & 33.3 & 40.2 \\
\hline
\end{tabular}

\subsubsection{Tensile strength}

Experimental tests on the tensile strength of masonry are scarce in the literature. We studied the tests performed by (Backes, 1985) on a series of walls using different types of masonry mortar and bricks, with 
different combinations of strength. Brick dimensions are $240 \mathrm{~mm}$ length, $115 \mathrm{~mm}$ depth and $113 \mathrm{~mm}$ height, with a $10 \mathrm{~mm}$ thickness of mortar joints. The specimen for testing is 490 x $482 \mathrm{~mm}$. We considered the results of the KS12 and HLz12 brick types and MGII and MGIII mortars. The properties of the materials are presented in Appendix A.

The principle of the test is to apply a direct tensile stress parallel to the bed joints with two metal beams glued to the wall (see (Backes, 1985) and (Lourenço, Rots, \& van der Pluijm, Understanding the tensile behaviour of masonry paralel to bed joints : a numerical approach, 1999) for further details). The rectangular prisms were modeled with a horizontal displacement set to zero on the left boundary, and a horizontal displacement imposed on the right boundary. Finite element size is about $5 \mathrm{~cm}$. The results show a good agreement with experimental results (Table 3).

Table 3 Comparison between the measured tensile strength (Backes, 1985) and numerical predictions (MPa)

\begin{tabular}{ccc}
\hline \multicolumn{1}{c}{ Prism } & Experimental & Model \\
\hline KS12-MG II & 0.17 & 0.19 \\
HLz12-MG III & 0.22 & 0.21 \\
\hline
\end{tabular}

\subsection{Validation in the case of a masonry vault}

Eventually, the model was used to simulate experimental tests performed by (Krajewski \& Hojdys, Experimental studies on buried barrel vaults, 2015) on semi-circular masonry vaults. Two particular cases are studied here (Fig. 5): the first one is a simple vault subjected to a point load, and the second one, a buried vault with a point load applied on the surface.

The vaults had two reinforced concrete supports connected with two steel rods with a diameter of $20 \mathrm{~mm}$, in order to avoid horizontal movements of the supports. For the buried vaults, concrete walls were built to retain the filling, connected by two steel beams to prevent horizontal displacements and rotations of the walls. The vault geometry is showed in Fig. 5. The bricks length, width and thickness are $250 \mathrm{~mm}, 125 \mathrm{~mm}$ and $65 \mathrm{~mm}$, respectively. The thickness of the mortar joints was $13 \mathrm{~mm}$. The properties of the materials are presented in Appendix A. 


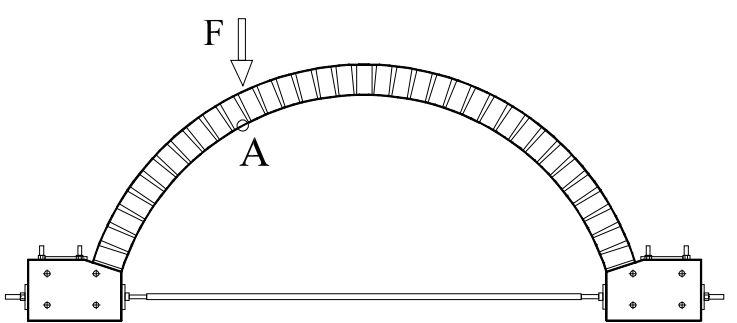

a) Vault without fill

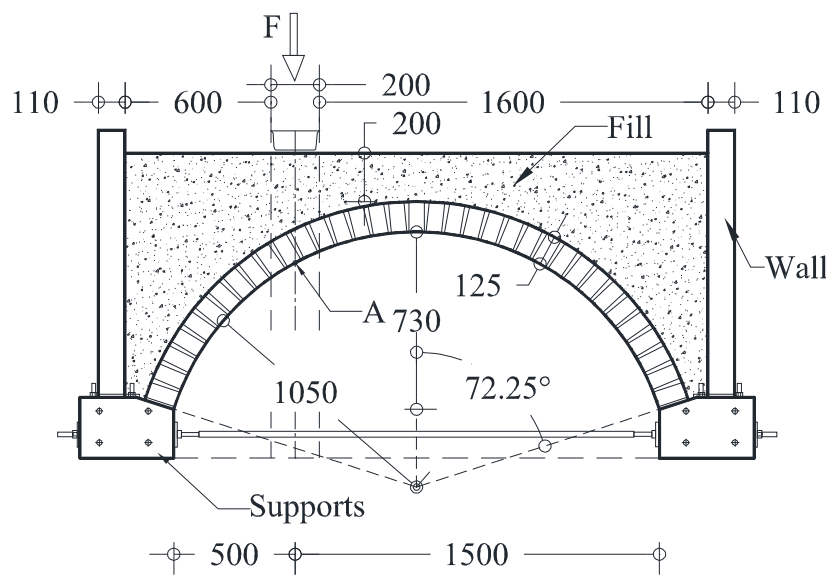

b) Buried vault

Fig. 5 Geometry of masonry arches semicircular studied by (Krajewski \& Hojdys, Experimental studies on buried barrel vaults, 2015) (in mm)

A set of LVDT sensors are placed in the vault intrados. Focus was taken only on the sensor positioned just below the load (point A, Fig. 5 a). The mean ellipse (see paragraph 3.4) is defined by $a=b=111.25 \mathrm{~cm}$ for both cases.

\subsubsection{Modelling of the vault without fill}

The FEM calculations were carried out in plane strain conditions. The applied boundary conditions in the vault are zero vertical and horizontal displacements in the supports. To deal with the softening behavior of the vault and avoid numerical instabilities, the structure is associated in the simulation with a fictitious spring placed at the point of application of the load. As damage evolves in the vault, the spring takes the difference between the external applied force and the force born by the vault.

The modeling results are shown in Fig. 6 and Table 4, where $u_{r}$ is the radial displacement of the vault of point A (Fig. 5 a). The angles in the numerical curve correspond to the formation of hinges in the loading process (Fig. 7). In the experimental results, the maximum load is reached for a small displacement, whereas in the calculations deformation is a little higher when maximum load is reached. However, from a qualitative point of view the model produces satisfactory results. 


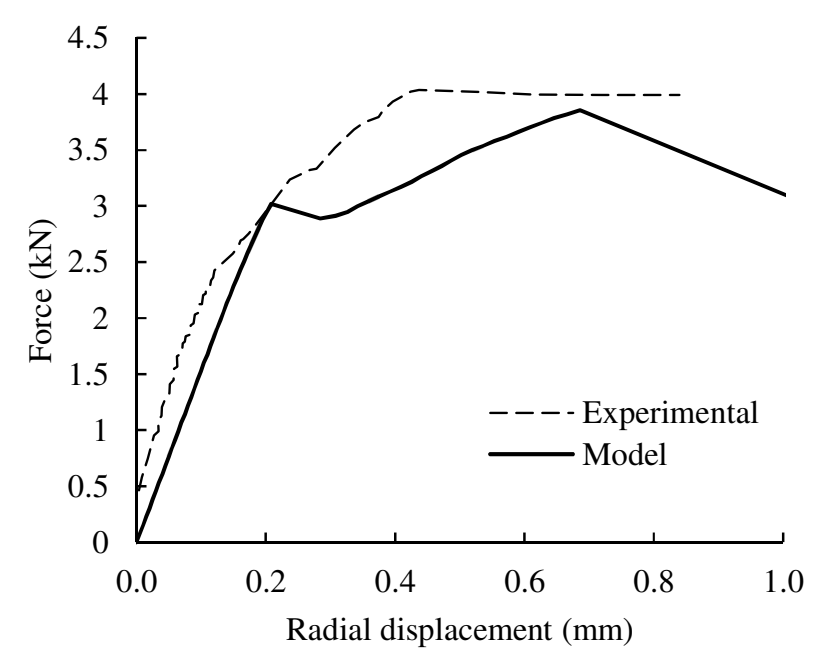

Fig. 6 Force-displacement curves for the vault without filling: experiment (Krajewski \& Hojdys, Experimental studies on buried barrel vaults, 2015) and numerical modeling
Table 4 Comparison of results

\begin{tabular}{lcc}
\hline & $F_{\max }(\mathrm{kN})$ & $u_{r}(\mathrm{~mm})$ \\
\hline Experimental & 4.10 & 0.43 \\
(Krajewski \& & & \\
Hojdys, & & \\
Experimental & & \\
studies on buried & & \\
barrel vaults, & & \\
2015) & & \\
Model & 3.86 & \\
\hline
\end{tabular}

In Fig. 7, the experimental and numerical failure mechanism of the vault are shown; notably, the four-hinge failure mechanism obtained experimentally (red dots) is correctly reproduced by the model. The hinges are identified in the numerical results as completely damaged zones where an abrupt change in the slope of the deformed shape takes place. The deviation between the simulation and the experiment can be attributed to numerous factors, notably the uncertainties on the details of the experimental setup (the type of contact between the vault and the support for instance).

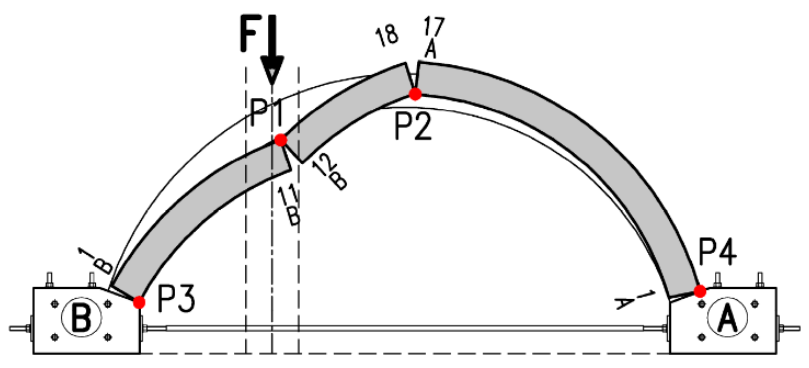

a) Experimental (Krajewski \& Hojdys, Experimental studies on buried barrel vaults, 2015), referred as specimen S02

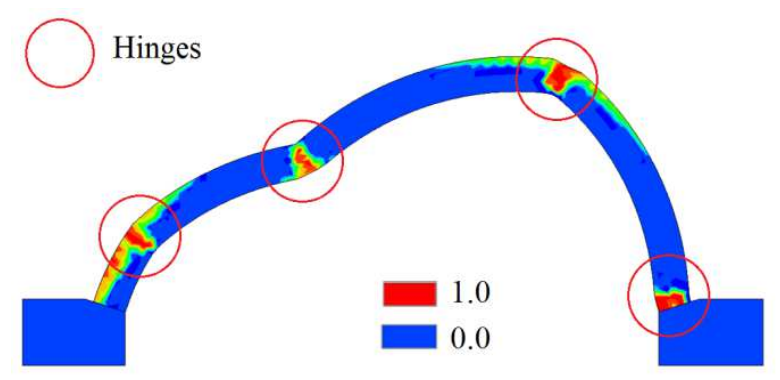

b) Numerical, damage variable $D_{22}$ ( $D=1$ complete damage; $D=0$ no damage)

Fig. 7 Failure mechanism of the vault without filling: comparison of experiment and modeling 


\subsubsection{Modelling of the buried vault}

The applied boundary conditions at the supports are zero vertical and horizontal displacements. Regarding the retaining walls of the fill (Fig. 5), we considered that there are no horizontal displacements of the walls, although a minor horizontal displacement of the upper edge of around $0.8 \mathrm{~mm}$ was measured. An elastoplastic model with a Drucker-Prager criterion was used for the filling, made of expanded clay, using the values given in Appendix A. Property values for masonry materials are also presented in Appendix A. The calculation was conducted in plane strain conditions in two steps: (1) application of the weight of the filling and vault and (2) application of the load in 100 increments.

The modeling results are shown in Fig. 8 and Table 5. The failure load is predicted with a good precision, the radial displacement $u_{r}$ of point A (see Fig. 5b), however, is a little less accurate. Fig. 9 shows that the model satisfactorily reproduces the four-hinge failure mechanism. Damage variable $D_{22}$ is shown to represent the damage state of the vault (see paragraph 3.5). As for the non-buried vault, the hinges are identified in the numerical results as completely damaged zones where an abrupt change in the slope of the deformed shape takes place.

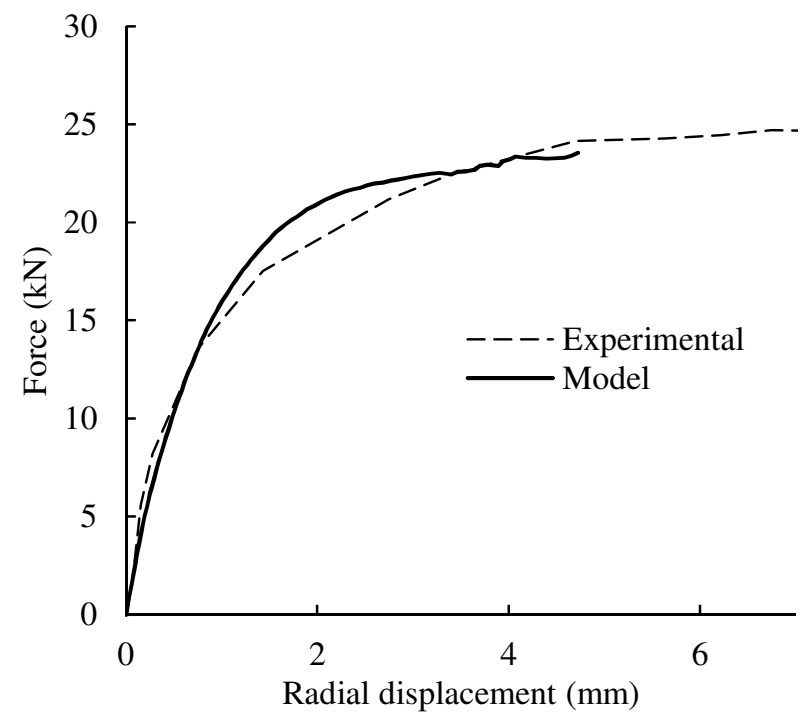

Table 5 Comparison of results

\begin{tabular}{lcc}
\hline & $F_{\max }(\mathrm{kN})$ & $u_{r}(\mathrm{~mm})$ \\
\hline Experimental & 24.70 & 6.75
\end{tabular}

(Krajewski \&

Hojdys, Experimental

studies on buried

barrel vaults, 2015)

Model

23.53

4.73

Fig. 8 Force-displacement curves for the buried vault: experiment (Krajewski \& Hojdys, Experimental studies on buried barrel vaults, 2015) and modeling 


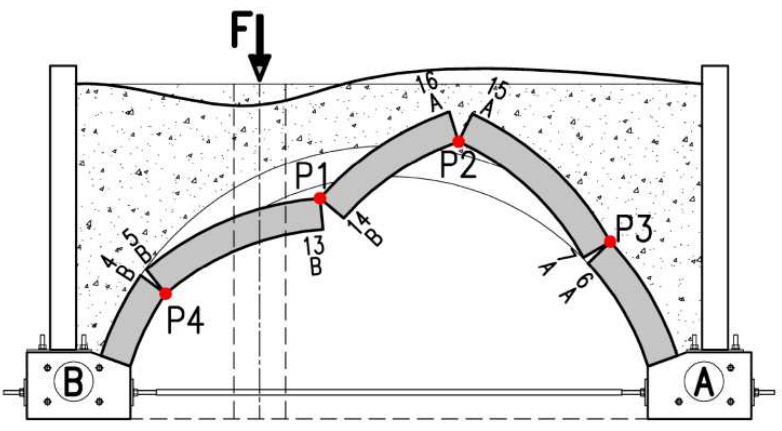

a) Experimental (Krajewski \& Hojdys, Experimental studies on buried barrel vaults, 2015), referred as

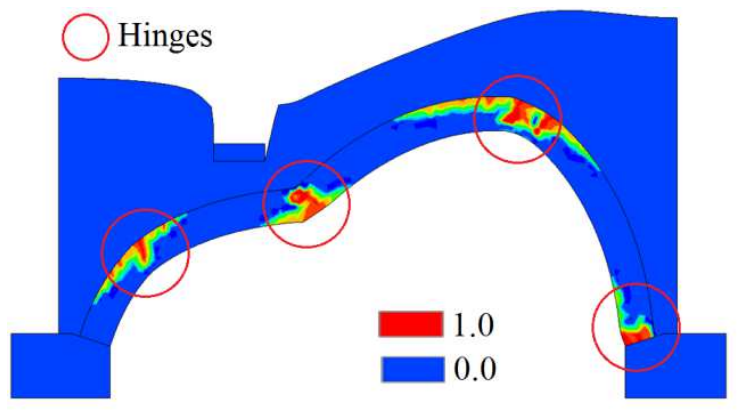

b) Numerical, damage variable $D_{22}$ ( $D=1$ complete damage; $D=0$ no damage)

specimen SKM

Fig. 9 Failure mechanism of the buried vault: comparison of experimental data and modeling

The small differences between experimental and numerical results showed in Fig. 8 and Fig. 9, can be due to the behavior of the fill and its interaction with the vault. The mechanical properties of the fill material have an influence on the way the applied load is transferred to the vault. A sensitivity analysis shows that a lower cohesion (a softer material) causes earlier numerical failure of the vault (Fig. 10).

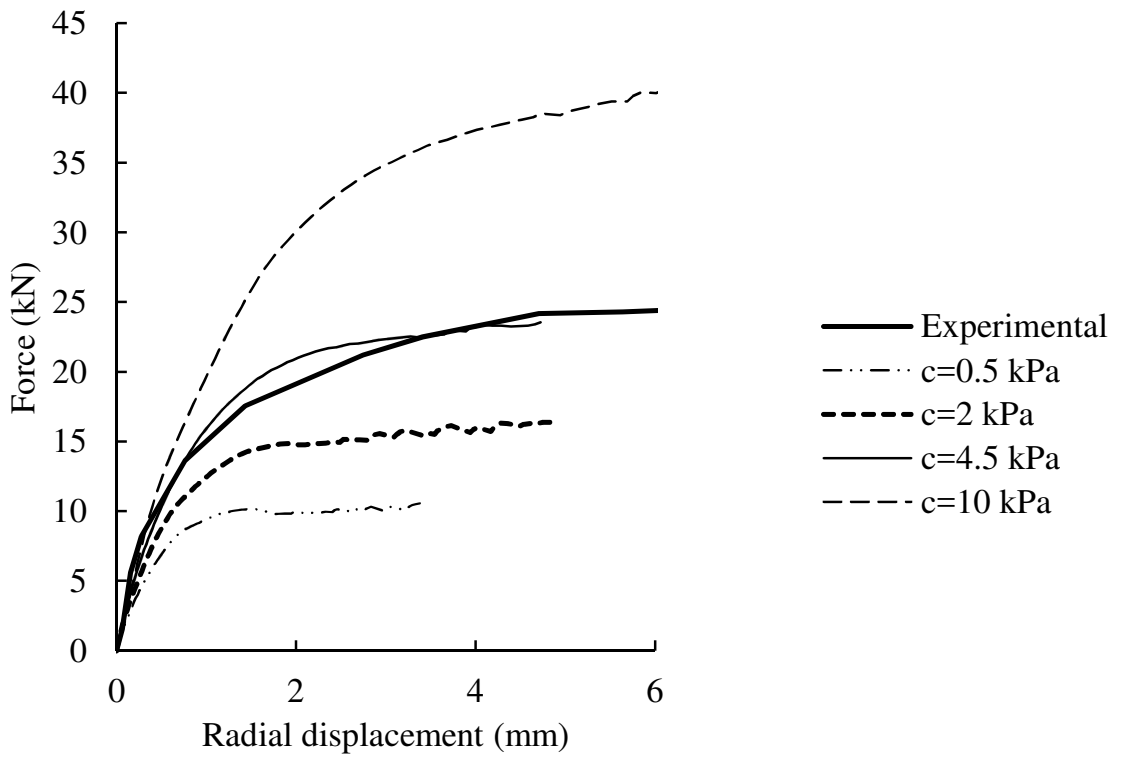

Fig. 10 Force-displacement curves for the buried vault with different cohesions 


\section{Conclusions}

A numerical model was proposed to analyze the nonlinear behavior of masonry vaults using a macromodeling strategy. The study includes the analyses of buried vaults up to failure. The nonlinear homogenization technique proposed by (Zucchini \& Lourenço, A coupled homogenisation-damage model for masonry cracking, 2004) was used to study the masonry with the following modifications: the nonlinear behavior of the components of the masonry is characterized by an isotropic damage model and the directions of the masonry in a vault were taken into account. The homogenization technique is modified to include a regularization technique to reduce the dependency of the solution with respect to the finite element mesh. The model was programmed in the finite element code CESAR-LCPC.

The model was used to reproduce elementary tests in tension and compression. A good agreement was found between experimental and numerical strengths. Secondly, the experimental tests conducted by (Krajewski \& Hojdys, Experimental studies on buried barrel vaults, 2015) on circular vaults, were reproduced numerically. Two cases were studied: a vault without filling and a buried vault. The model satisfactorily reproduces the failure load, the four-hinge failure mechanism, and it is also possible to evaluate the deformation of the structure during loading process up to failure. The simulations also show that the mechanical properties of the fill material have an influence on the way the applied load is transferred to the vault.

The proposed model can be used to study any masonry vault, whose geometry can be represented by an elliptical curve. This model will be used for the masonry vaults of the Paris metro, in order to evaluate the serviceability state when nearby civil engineering works alter the original equilibrium state of the structure.

\section{Acknowledgements}

This paper is based on the PhD thesis of the first author (Moreno Regan, 2016), developed in the framework of the CIFRE convention 2012-1605 between IFSTTAR, and the administrator of the Paris metro, RATP. 


\section{Appendix A}

In the tables presented in this appendix, the following notation is used:

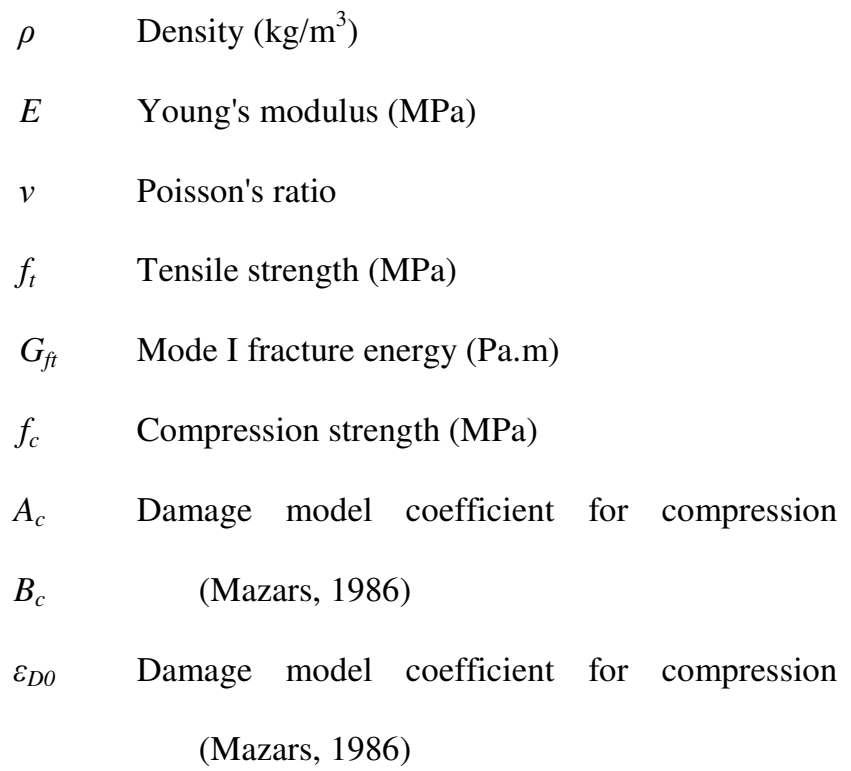

In all cases the parameters $A_{c}$ and $B_{c}$ were proposed in such a way as to obtain the value of the peak stress in the strain-stress curve equals the known compressive strength. Damage threshold strains were calculated with $\varepsilon_{D 0}=f_{t} / E_{0}$. 
Table A.1 Properties of mortar and brick for the validation of the compressive and tensile tests

\begin{tabular}{|c|c|c|c|c|c|c|c|}
\hline \multirow[t]{2}{*}{ Ref } & \multicolumn{3}{|c|}{$\begin{array}{c}\text { McNary \& Abrams (McNary \& } \\
\text { Abrams, 1985) }\end{array}$} & \multicolumn{4}{|c|}{ Backes (Backes, 1985) } \\
\hline & Unit1 & Unit 2 & Mortar M & Unit KS12 & Mortar MG II & Unit HLZ 12 & Mortar MG III \\
\hline$E$ & $15000^{*}$ & 9900* & $11600 *$ & $4500 * *$ & $1120^{* * *}$ & $3500 * *$ & $1832 * *$ \\
\hline$v$ & $0.13 *$ & $0.17 *$ & $0.096^{*}$ & 0.2 & 0.2 & 0.2 & 0.2 \\
\hline$f_{t}$ & $2.74 *$ & $1.79 *$ & 2.97 & $1.44 * *$ & 0.13 & $0.9 * *$ & 0.15 \\
\hline$G_{f t}$ & $79 *$ & $52 *$ & 100 & 150 & 9.0 & 100 & 10 \\
\hline$f_{c}$ & $58.9 *$ & $44 *$ & $31.1 *$ & $23.2 * *$ & $3.5 * *$ & $23.3 * *$ & $9.86^{* *}$ \\
\hline$A_{c}$ & 1.15 & 1.1 & 0.8 & 1.0 & 0.8 & 1.0 & 1.0 \\
\hline$B_{c}$ & 634 & 400 & 1318 & 275 & 356 & 206 & 246 \\
\hline$\varepsilon_{D 0}$ & $1.84 \mathrm{E}-4$ & $1.81 \mathrm{E}-4$ & $2.65 \mathrm{E}-4$ & $3.2 \mathrm{E}-4$ & $1.16 \mathrm{E}-4$ & $2.57 \mathrm{E}-4$ & $8.19 \mathrm{E}-5$ \\
\hline
\end{tabular}

*Properties taken from (Zucchini \& Lourenço, Mechanics of masonry in compression: Results from a homogenisation approach, 2007) other properties were proposed.

**Properties taken from (Backes, 1985). The elasticity modulus have been proposed in such a way that after the homogenization process, we find the value of the masonry modules in tension measured by (Backes, 1985), i.e. $E=3870$ and 3273 MPa for walls KS12-MGII and HLz12-MG III, respectively. Other properties were proposed 
Table A.2 Properties of mortar and brick for the validation of the masonry vault

\begin{tabular}{|l|cc|cc|}
\hline \multirow{2}{*}{ Ref } & \multicolumn{3}{|c|}{ Krajewski \& Hojdys (Krajewski \& Hojdys, Experimental } \\
& \multicolumn{3}{|c|}{ studies on buried barrel vaults, 2015) } \\
\hline \multirow{2}{*}{} & \multicolumn{2}{|c|}{ vault without fill } & \multicolumn{2}{c|}{ buried vault } \\
\cline { 2 - 5 } & Unit & Mortar & Unit & Mortar \\
\hline$\rho$ & $1700^{*}$ & $1700^{*}$ & $1700^{*}$ & $1700^{*}$ \\
$v$ & 10000 & $250^{*}$ & 10000 & 150 \\
$f_{t}$ & $0.2^{*}$ & $0.16^{*}$ & $0.2^{*}$ & $0.16^{*}$ \\
$G_{f t}$ & 0.9 & $0.08^{*}$ & 0.9 & $0.08^{*}$ \\
$f_{c}$ & 100 & 10 & 100 & 30 \\
$A_{c}$ & $24.4^{*}$ & $1.0^{*}$ & $21.4^{*}$ & $1.1^{*}$ \\
$B_{c}$ & 1.0 & 0.5 & 1.0 & 0.5 \\
$\varepsilon_{D O}$ & 561 & 269 & 644 & 142 \\
\hline
\end{tabular}

*Properties taken from and (Hojdys, Kaminski, \& Krajewski, 2013b), (Krajewski \& Hojdys, Burried vaults with different types of extrados finishes - experimental tests, 2014) and (Krajewski \& Hojdys, Experimental studies on buried barrel vaults, 2015), other properties were proposed

Table A.3 Properties of the fill from of the buried vault

\begin{tabular}{lc}
\hline & Expanded clay \\
\hline$\rho$ & $300^{*}$ \\
$E$ & 10 \\
$v$ & 0.3 \\
Cohesion $(\mathrm{kPa})$ & 4.5 \\
Friction angle $\left(^{\circ}\right)$ & $37^{*}$ \\
Dilatancy angle $\left(^{\circ}\right)$ & 10 \\
\hline
\end{tabular}

*Properties taken from (Krajewski \& Hojdys, Experimental studies on buried barrel vaults, 2015), other properties were proposed 


\section{References}

Addessi, D., \& Sacco, E. (2012). A multi-scale enriched model for the analysis of masonry panels. International Journal of Solids and Structures, 49(6), 865-880.

Addessi, D., Marfia, S., \& Sacco, E. (2002). A plastic nonlocal damage model. Computer Methods in Applied Mechanics and Engineering, 191, 1291-1310.

Angelillo, M. (2014). Mechanics of Masonry Structures. Springer-Verlag Wien.

Backes, H.-P. (1985). Tensile strength of masonry. In T. McNeilly, \& J. C. Scrivener (Ed.), Proceedings of the 7th International Brick Masonry Conference, Melbourne, Australia, (pp. 779-790).

Benvenuto, E. (1991). An Introduction to the History of Structural Mechanics: Part II: Vaulted Structures and Elastic Systems. Springer New York.

Berto, L., Saetta, A., Scotta, R., \& Vitaliani, R. (2004). Shear behaviour of masonry panel: parametric FE analyses. International Journal of Solids and Structures, 41, 4383-4405.

Callerio, A., \& Papa, E. (1998). An elastic-plastic model with damage for cyclic analysis of masonry panels. Computer Methods in Structural Masonry - 4, 19-26.

Creazza, G., Matteazzi, R., Saetta, A., \& Vitaliani, R. (2002). Analyses of Masonry Vaults: A Macro Approach based on Three-Dimensional Damage Model. Journal of Structural Engineering, 128(5), pp. 646-654.

Davenne, L., Saouridis, C., \& Piau, J. (1989). Un code de calcul pour la prévision du comportement de structures endommageables en béton, en béton armé ou en béton de fibres. Annales de l'Institut technique du bâtiment et des travaux publics, No. 478, 137-156.

Delbecq, J. (1982). Les ponts en maçonnerie. Constitution et Stabilité. Ministère des Transports. Direction des routes. Département des Ouvrages d'Art du SETRA.

Domède, N. (2006). Méthode de requalification des ponts en maçonnerie. Institut National de Sciences Appliquées de Toulouse, France. PhD Thesis, INSA Toulouse (in French).

Domede, N., Sellier, A., \& Stablon, T. (2013). Structural analysis of a multi-span railway masonry bridge combining in situ observations, laboratory tests and damage modelling. Engineering Structures, $56(0), 837-849$.

Greco, F., Leonett, L., Luciano, R., \& Nevone Blasi, P. (2016, October). An adaptive multiscale strategy for the damage analysis of masonry modeled as a composite material. Composite Structures, 153(1), 972-988.

Heyman, J. (1969). The safety of masonry arches. International Journal of Mechanical Sciences, 11(4), 363385.

Heyman, J. (1997). The Stone Skeleton. Cambridge University Press.

Hojdys, L., Kaminski, T., \& Krajewski, P. (2013b). Experimental and numerical simulation of collapse of masonry arches. ARCH '13. Proceedings of the 7th International Conference on Arch Bridges. Trogir-Split, Croatia. October 4-6, 2013, (pp. 715-722).

Krajewski, P., \& Hojdys, L. (2014). Burried vaults with different types of extrados finishes - experimental tests. In F. P. Chávez (Ed.), 9th International Conference on Structural Analysis of Historical Constructions. Mexico City, Mexico, 14-17 October 2014.

Krajewski, P., \& Hojdys, L. (2015). Experimental studies on buried barrel vaults. International Journal of Architectural Heritage, 9(7), 834-843. 
La Borderie, C. (2003). Stratégies et Modèles de Calculs pour les Structures en Béton. Ph.D. dissertation, Thèse présentée pour l'obtention de l'habilitation à diriger les recherches. Université de Pau et des Pays de l'Adour, France.

Lemaitre, J. (1992). A course in damage mechanics. (Springer-Verlag, Ed.) Springer-Verlag.

Lemaitre, J., \& Desmorat, R. (2005). Engineering Damage Mechanics (Springer Berlin Heidelberg ed.). (S. B. Heidelberg, Ed.) The Netherlands.

Livesley, R. K. (1978). Limit analysis of structures formed from rigid blocks. International Journal for Numerical Methods in Engineering, 12(12), 1853-1871.

Lourenço, P. (1996). Computational Strategies for Masonry Structures. Technische Universiteit Delf. PhD Thesis, Delft University Press.

Lourenço, P., Milani, G., Tralli, A., \& Zucchnini, A. (2007). Analysis of masonry structures : review of and recent trends in homogenization techniques. Canadian Journal of Civil Engineering, 34, 1443-1457.

Lourenço, P., Rots, J., \& van der Pluijm, R. (1999). Understanding the tensile behaviour of masonry paralel to bed joints : a numerical approach. Masonry International, 12(3), 96-103.

Luciano, R., \& Sacco, E. (1997). Homogenization technique and damage model for old masonry material. International Journal of Solids and Structures, 34(24), 3191-3208.

Maier, G., Papa, E., \& Nappi. (1991). Experimental and numerical methods in earthquake engineering. In J. Donea, \& P. Jones (Eds.). Kluwer Academic.

Massart, T., Peerlings, R., \& Geers, M. (2004). Mesoscopic modeling of failure and damage-induced anisotropy in brick masonry. European Journal of Mechanics and Solids, 23(5), 719-735.

Mazars, J. (1986). A description of micro- and macroscale damage of concrete structures. Engineering Fracture Mechanics, 25, 729-737.

McNary, W. S., \& Abrams, D. P. (1985). Mechanics of Masonry in Compression. Journal of Structural Engineering, 111(4), 857-870.

Moreno Regan, O. (2016). Study of the behavior of the masonry tunnels of the Paris subway system (in French). Ph.D. dissertation, Paris, France : Université Paris-Est.

Murakami, S. (2012). Continuum Damage Mechanics. A Continuum Mechanics Approach to the Analysis of Damage and Fracture (1 ed.). (S. Netherlands, Ed.) Springer Netherlands.

Papa, E. (1995). Damage models for masonry structures. Engineering Mechanics.

Pelà , L., Cervera, M., \& Roca, P. (2011). Continuum damage model for orthotropic materials: Application to masonry. Computer Methods in Applied Mechanics and Engineering, 200, 917-930.

Quinteros, R., Oller, S., \& Nallim, L. G. (2012). Nonlinear homogenization techniques to solve masonry structures problems. Composite Structures, 94(2), 724-730.

Roca, P., Cervera, M., Gariup, G., \& Pela, L. (2010). Structural Analysis of Masonry Historical Constructions. Classical and Advanced Approaches. Archives of Computational Methods in Engineering, 17(3), 299-325.

Salençon, J. (1983). Calcul à la rupture et analyse limite. (P. Presses de l'ENPC, Ed.) Presses de l'ENPC, Paris.

Stablon, T., Sellier, A., Domede, N., Plu, B., \& Dieleman, L. (2012, June). Influence of building process on stiffness: numerical analysis of a masonry vault including mortar joint shrinkage and crack reclosure effect. Materials and Structures, 45(6), 881-898. 
Tesei, C., \& Ventura, G. (2016). A unilateral nonlocal tensile damage model for masonry structures. Procedia Structural Integrity, 2, 2690-2697.

Toti, J., Gattulli, V., \& Sacco, E. (2015, May). Nonlocal damage propagation in the dynamics of masonry elements. Computers \& Structures, 152, 215-227.

Uva, G., \& Salerno, G. (2006). Towards a multiscale analysis of periodic masonry brickwork: A FEM algorithm with damage and friction. International Journal of Solids and Structures, 43(13), 37393769 .

Wawrzynek, A., \& Cincio, A. (2005). Plastic-damage macro-model for non-linear masonry structures subjected to cyclic or dynamic loads. Proceedings of Conf. Analytical Models and New Concepts in Concrete and Masonry Structures, AMCM'2005. Gliwice, Poland.

Zahra, T., \& Dhanasekar, M. (2016, April). Prediction of masonry compressive behaviour using a damage mechanics inspired modelling method. Construction and Building Materials, 109, 128-138.

Zucchini, A., \& Lourenço, P. (2002). A micro-mechanical model for the homogenisation of masonry. International Journal of Solids and Structures, 39, 3233-3255.

Zucchini, A., \& Lourenço, P. (2004). A coupled homogenisation-damage model for masonry cracking. Computers and Structures, 82(11-12), 917-929.

Zucchini, A., \& Lourenço, P. (2007). Mechanics of masonry in compression: Results from a homogenisation approach. Computers and Structures, 85(3-4), 193-204.

Zucchini, A., \& Lourenço, P. (2009). A micro-mechanical homogenisation model for masonry: Application to shear walls. International Journal of Solids and Structures , 46(3-4), 871-886. 